\title{
A Decade of Experience with the Ovine Model of Myelomeningocele: Risk Factors for Fetal Loss
}

\author{
Laura A. Galganski ${ }^{a} \quad$ Kaeli J. Yamashiro ${ }^{a} \quad$ Christopher D. Pivetti $^{a}$ b \\ Benjamin A. Keller ${ }^{a}$ James C. Becker ${ }^{a}$ Erin G. Brown ${ }^{a, b}$ Payam Saadai ${ }^{a}, b$ \\ Shinjiro Hirose ${ }^{a, b}$ Aijun Wang ${ }^{a-c}$ Diana L. Farmer ${ }^{a, b}$ \\ ${ }^{\text {a }}$ Department of Surgery, University of California-Davis, Sacramento, CA, USA; ${ }^{6}$ Shriners Hospitals for \\ Children Northern California, Sacramento, CA, USA; ${ }^{C}$ Department of Biomedical Engineering, University of \\ California-Davis, Davis, CA, USA
}

\section{Keywords}

Fetal surgery $\cdot$ Myelomeningocele $\cdot$ Spina bifida $\cdot$ Animal disease models · Fetal research

\begin{abstract}
Introduction: The ovine model is the gold standard large animal model of myelomeningocele (MMC); however, it has a high rate of fetal loss. We reviewed our experience with the model to determine risk factors for fetal loss. Methods: We performed a retrospective review from 2009 to 2018 to identify operative factors associated with fetal loss (early fetal demise, abortion, or stillbirth). Operative risk factors included gestational age at operation, operative time, reduction of multiple gestations, amount of replaced amniotic fluid, ambient temperature, and method of delivery. $\boldsymbol{R} \boldsymbol{e}$ sults: MMC defects were created in 232 lambs with an overall survival rate of $43 \%$. Of the 128 fetuses that died, 53 (42\%) had demise prior to repair, 61 (48\%) aborted, and 14 (11\%) were stillborn. Selective reduction of multiple gestations in the same uterine horn was associated with increased fetal
\end{abstract}

demise (OR 3.03 [95\% Cl 1.29-7.05], $p=0.01$ ). Later gestational age at $\mathrm{MMC}$ repair and Cesarean delivery were associated with decreased abortion/stillbirth (OR $0.90[95 \% \mathrm{Cl}$ $0.83-0.90$ ], $p=0.03$, and OR 0.37 [95\% Cl 0.16-0.31], $p=$ $0.02)$, respectively. Conclusion: Avoiding selective reduction, repairing MMC later in gestation, and performing $\mathrm{Ce}$ sarean delivery decreases the rate of fetal loss in the ovine MMC model.

๑) 2020 S. Karger AG, Basel

\section{Introduction}

Myelomeningocele (MMC) results from failure of neural tube closure in early gestation and leads to lower extremity paralysis, bowel and bladder dysfunction, and hindbrain herniation [1]. Clinical and experimental evidence suggested that the paralysis associated with MMC was partly due to intrauterine chemical and mechanical trauma and, therefore, was partially preventable [2]. Following initial evidence in small and large animal models karger@karger.com

www.karger.com/fdt

Karger ${ }^{\prime}=$
(C) 2020 S. Karger AG, Basel
Laura A. Galganski, MD

Department of Surgery, University of California-Davis 2335 Stockton Blvd, Room 5107

Sacramento, CA 95817 (USA)

lgalganski@ucdavis.edu 
of MMC, the Management of Myelomeningocele Study (MOMS) confirmed that in utero surgical repair improves lower extremity function in children with MMC [3-6]. However, 58\% of children treated with in utero surgery were still unable to walk independently, leading to further translational studies to augment the in utero surgery in the ovine model $[7,8]$.

The ovine model is the gold standard large animal model for studying in utero treatment of MMC due to anatomic size allowing for surgical instrumentation, pregnancies with multiple gestations, gestation length allowing study of disease pathogenesis and treatment, and relative tolerance of multiple uterine surgeries [9]. However, the ovine model is limited by expense and high rates of fetal loss [4, 10-12]. Previous studies have reported fetal loss following both in utero surgical MMC model creation and surgical MMC repair [11, 13, 14]. Given our experience with the ovine model over the past decade, we sought to evaluate the risk factors for fetal loss. We hypothesized that lower ambient temperatures at parturition and Cesarean delivery were associated with lower rates of fetal loss.

\section{Materials and Methods}

\section{Time-Mated Ewes}

Time-mated ewes (Ovis aries) were obtained from two vendors during the study period: 2009 to 2018 . The vendors tested ewes for Coxiella burnetii ( $\mathrm{Q}$ fever) prior to mating and confirmed pregnancies with ultrasound. Ewes were delivered to the University of California, Davis regardless of the number of gestations 7-14 days prior to surgery for acclimation and repeat Q fever testing. Prior to surgery, ewes were fasted for $12 \mathrm{~h}$. Ewes and lambs were housed pre- and postoperatively in a natural indoor, open-air barn environment.

The University of California Davis Institutional Animal Care and Use Committee (IACUC) approved all animal protocols, and all animal care was in compliance with the Guide for the Care and Use of Laboratory Animals. All facilities used during the study period were accredited by the Association for the Assessment and Accreditation of Laboratory Animal Care International.

\section{Maternal and Fetal Anesthesia}

Anesthesia was induced with intravenous ketamine $(4 \mathrm{mg} / \mathrm{kg})$ and propofol $(5 \mathrm{mg} / \mathrm{kg})$. Ewes were orotracheally intubated and mechanically ventilated to achieve approximately $7 \mathrm{~mL} / \mathrm{kg}$ tidal volume. General anesthesia was maintained with isoflurane (1.75$3 \%)$. Antibiotic prophylaxis with ceftiofur (1.1-2.2 $\mathrm{mg} / \mathrm{kg}$ i.v.) was administered preoperatively. Fetal anesthesia was provided via maternal-fetal circulation of isoflurane. In the event of fetal movement during the operation, the isoflurane concentration was increased, and the operation was paused until the cessation of fetal movement. The anesthetic technique was consistent throughout the review period.

\section{Defect Creation}

An ultrasound was performed to confirm fetal viability prior to the MMC operation. The number of gestations was estimated at the time of preoperative ultrasound, though intraoperative confirmation was required. Defects were surgically created at $75 \pm 7$ days of gestation based on initial research that the MMC defect created at 75 days of gestation had less spontaneous healing than at 60 days [10]. Following maternal laparotomy and hysterotomy, the MMC defect was created by removing the skin, paraspinal muscles, and posterior vertebral lamina and dura overlying 6 lumbar segments as previously described (Fig. 1) [7]. This large defect avoids complete healing of the defect prior to repair. A defect creation score is documented to account for injury to the spinal cord at the time of the MMC defect creation [12]. No myelotomy was performed in this series of experiments as the focus was specifically on motor function rather than the consequences of hindbrain herniation. Amniotic fluid was replaced with a recorded volume of warm normal saline, and antibiotics (1 million units of penicillin and $100 \mathrm{mg}$ of gentamicin) were added to the amniotic fluid prior to hysterotomy closure.

During the majority of the study period, multiple gestations in the same uterine horn were reduced through a second hysterotomy in order to minimize growth restriction and on the assumption that it would improve fetal survival in the experimental animals. Thus, only one defect and repair was performed in each horn of the uterus.

\section{Repair}

MMC repairs were performed at $100 \pm 7$ days of gestation based on initial reports of fetal MMC repair in the model $[4,13]$. Innate healing from the time of MMC defect creation was documented with a validated score [12]. Repair strategies varied during the study and included closure of skin only or application of autologous amniotic membrane, nanofiber scaffold patch, collagen hydrogel with or without neural crest stem cells or placenta-derived mesenchymal stem cells (PMSCs), or extracellular matrix patch with or without PMSCs [7, 8, 15-19].

\section{Delivery and Lamb Resuscitation}

From 2009 to 2015, lambs were delivered via spontaneous vaginal delivery (SVD). Following an observation of dystocia and increased stillbirth in some lambs born via SVD, starting in 2016, lambs underwent Cesarean delivery at term (146 days of gestation) if they had not previously been born via SVD. Cesarean delivery was performed at term in order to limit negative effects of prematurity. Following Cesarean delivery, lambs required resuscitation due to maternal-fetal anesthesia. The lambs' oropharynges were suctioned, followed by endotracheal intubation and ventilation, until the lambs were breathing spontaneously and demonstrated adequate head control. Additionally, lambs were dried with towels and warmed with a heated air blanket. Lamb hind limb motor function was scored from 0 to 15 with a validated Sheep Locomotor Rating Scale shortly after birth and $24 \mathrm{~h}$ later [20]. The vast majority of the Cesarean deliveries during the study were terminal procedures for the ewes. Lambs were then bottle fed until the study endpoint. Anecdotally, we have had success with achieving ewelamb bonding after survival Cesarean delivery by placing amniotic-fluid soaked towels on the ewe's nares and by exposing ewes to the newly delivered lambs during the anesthesia emergence and recovery period. 
Fig. 1. a Myelomeningocele defect. The MMC defect is created by removal of skin, subcutaneous tissue, and paraspinal muscles of six lumbar vertebrae. b A posterior laminectomy exposes the spinal cord before the dura is removed.
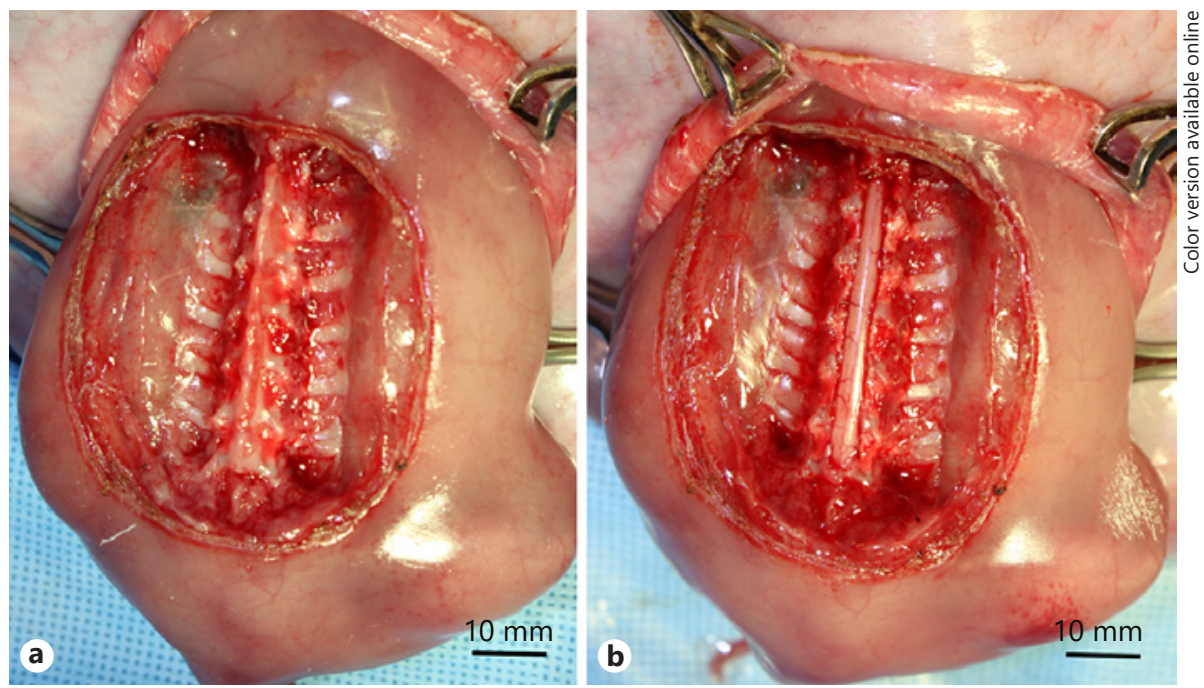

Following each operation, ewes received buprenorphine (0.005-0.1 mg/kg i.m.) every $12 \mathrm{~h}$ for the first $48 \mathrm{~h}$ for pain control. Ceftiofur (1.1-2.2 mg/kg i.m.) was administered daily for 5 days postoperatively.

\section{Statistical Analysis}

Results are reported as medians (interquartile range). To assess operative factors associated with fetal loss, we used a generalized logistic model while accounting for correlation among lambs from the same ewe. Fetal demise was defined as loss prior to MMC repair. Abortion was defined as fetal loss subsequent to MMC repair and prior to 138 days of gestation, and stillbirths were lambs that were born dead after 139 days of gestation or that died during birth. Analysis was performed in SAS version 9.4 (SAS Institute Inc., Cary, NC, USA) with significance set at $p<0.05$.

\section{Results}

\section{Summary of Animal Numbers}

From 2009 to 2018, a total of 142 ewes were operated on, $71 \%$ of which had multiple gestations (mostly twins, with up to 5 fetuses). 225 MMC defects were created and 172 MMC repairs were performed. Fifty-three of the 225 fetuses had MMC defects only due to fetal demise prior to repair. A total of 41 fetuses that were part of a multiple gestation pregnancy were reduced. Additionally, 5 control lambs were used to define normal imaging and histologic parameters.

\section{Operative Results}

The median gestation age for MMC creation was 77 days (IQR 77-79). The median operative time for defect creation for each fetus was 34 min (IQR 28-41) with a median ewe operative time of $124 \mathrm{~min}$ (IQR 98-144). The median saline added to each uterine horn during creation was $700 \mathrm{~mL}$ (IQR 500-850). For MMC repair, the median gestational age was 101 days of gestation (IQR 99-105) with a median time between defect creation and repair of 26 days (IQR 22-28). The median operative time for MMC repair of each fetus was 50 min (IQR 39-64) with a median ewe operative time of $164 \mathrm{~min}$ (IQR 128-201). The median saline added at repair was $1,000 \mathrm{~mL}$ (IQR $750-1,260)$. Cesarean delivery was performed on $43.8 \%$ $(n=60)$ of ewes at a median gestational age of 146 days (IQR 140-147).

\section{Ewe Complications}

Seven ewes were euthanized. These were due to partial fascial dehiscence secondary to superficial surgical site infection $(n=3)$, postoperative respiratory complications $(n=1)$, pregnancy toxemia $(n=1)$, straddle injury $(n=$ $1)$, and postoperative weight loss $(n=1)$.

\section{Fetal Loss}

There were 2 fetal demises prior to defect creation. Following defect creation, 128 fetuses were lost due to fetal demise $(n=53,41 \%)$, abortion $(n=61,48 \%)$, or stillbirth $(n=14,11 \%)$. All surviving fetuses subsequently underwent MMC defect repair. The rate of fetal survival following MMC defect creation (76.4\%) was significantly higher than survival following MMC defect repair (56.4\%) $(p<$ 0.001 ) During the study period, the overall survival rate was $43 \%$, which varied by academic year (Table 1 ). Academic year, which accounts for operator involvement, was not associated with fetal loss (OR 0.97 [96\% CI 0.84-1.11]). 
Table 1. Survival rate by academic year

\begin{tabular}{lrrrrrrrrr}
\hline & 2009 & 2010 & 2011 & 2012 & 2013 & 2014 & 2015 & 2016 & 2017 \\
\hline Lambs, $n$ & 3 & 23 & 7 & 18 & 35 & 15 & 36 & 39 & 49 \\
Survival rate, \% & 100 & 48 & 57 & 33 & 26 & 27 & 56 & 41 & 49 \\
\hline
\end{tabular}

Survival rate ranged from 26 to $100 \%$ from 2009 to $2017(p=0.063)$.

Table 2. Factors associated with fetal demise or abortion

\begin{tabular}{|c|c|c|c|}
\hline & Median (IQR) or $n(\%)$ & Odds ratio $(95 \% \mathrm{CI})$ & $p$ value \\
\hline \multicolumn{4}{|l|}{ Defect creation } \\
\hline Gestational age, days & $77(77-79)$ & $1.06(0.92-1.22)$ & 0.43 \\
\hline Fetus operative time, min & $34(28-41)$ & $1.01(0.99-1.03)$ & 0.29 \\
\hline Ewe operative time, $\min$ & $124(98-144)$ & $1.00(0.99-1.02)$ & 0.19 \\
\hline Volume of added saline, $\mathrm{mL}$ & $700(500-850)$ & $1.00(0.99-1.00)$ & 0.42 \\
\hline Reduction of multiple gestation & $41(14.8)$ & $3.03(1.29-7.05)$ & $0.01^{*}$ \\
\hline \multicolumn{4}{|l|}{ Defect repair } \\
\hline Days since defect creation, days & $26(22-28)$ & $0.82(0.73-0.91)$ & $<0.001^{*}$ \\
\hline Gestational age, days & $101(99-105)$ & $0.90(0.83-0.90)$ & $0.03^{*}$ \\
\hline Fetus operative time, min & $50(39-64)$ & $1.07(0.96-1.20)$ & 0.25 \\
\hline Ewe operative time, $\min$ & $164(128-201)$ & $1.01(0.99-1.01)$ & 0.18 \\
\hline Volume of added saline, $\mathrm{mL}$ & $1,000(750-1260)$ & $1.00(0.99-1.00)$ & 0.13 \\
\hline \multicolumn{4}{|l|}{ Delivery } \\
\hline Ambient high temperature, ${ }^{\circ} \mathrm{F}$ & $75(66-86)$ & $1.00(0.97-1.02)$ & 0.70 \\
\hline Gestational age, days & $146(140-147)$ & $0.94(0.87-1.03)$ & 0.18 \\
\hline Cesarean delivery & $60(43.8)$ & $0.37(0.16-0.31)$ & $0.02 *$ \\
\hline
\end{tabular}

The only operative factor during defect creation associated with increased fetal loss was performing a selective reduction in a single uterine horn with multiple gestations (OR 3.03 [95\% CI 1.29-7.05], $p=0.01$ ). Other operative factors during defect creation including gestational age, ewe and fetal operative time, and amount of saline added to the uterus were not significantly associated with fetal loss (Table 2).

The interval timing of MMC repair was significantly associated with fetal loss. A longer interval between defect creation and repair was associated with decreased fetal loss (OR 0.82 [95\% CI 0.73-0.91], $p<0.001$ ). For every additional day between defect creation and repair there was a 0.82 odds of fetal death. Similarly, later gestational age at repair was associated with decreased fetal loss (OR 0.90 [95\% CI 0.83-0.90], $p=0.03$ ). For every additional day of gestation at time of MMC repair, there was a 0.90 odds of fetal loss. Neither operative time for the fetus or ewe nor the volume of added saline was associated with fetal loss during MMC defect creation or repair.

The method of delivery was also significantly associated with fetal loss. For those lambs reaching term, Cesarean delivery was associated with a decreased fetal loss (OR 0.37 [95\% CI 0.16-0.31], $p=0.02$ ). Ambient outdoor temperature and gestational age at delivery were not associated with fetal loss (Table 2).

\section{Discussion}

This is the largest reported series using the surgically created ovine model of MMC. The overall survival rate, from the time of MMC defect creation to live birth, in this study was $43 \%$. Reduction of multiple gestations, de- 
creased time between MMC defect creation and repair, and earlier gestational age at MMC repair were associated with increased fetal loss. Contrary to the hypothesis, ambient temperature at parturition was not significantly associated with fetal loss. However, Cesarean delivery was associated with decreased fetal loss. After transitioning to routine Cesarean delivery, the survival rate improved from 40 to $46 \%$.

The reported rate of survival in this study is within the range of previously published rates ranging from 25 to $87 \%[5,10,11,14,21,22]$. Some variation in these published rates can be explained by small experimental series, inclusion of sham controls, and inclusion of maternal deaths. Our practice of multiple gestation fetal reduction and a large six lumbar level MMC defect creation may explain our increased rate of early fetal demise; however, the explanation of our higher rate of late abortion and stillbirths remains unclear. While transitioning to Cesarean delivery, as was performed in all but one of the published studies, has improved our survival, we continue to have a large number of stillbirths. One explanation of higher rates of stillbirth may be our practice of performing Cesarean delivery near term at 146 days of gestation, while other investigators have chosen an earlier delivery at 140 days with better survival and potentially fewer deaths from dystocia $[11,14,23]$.

Fetal loss was increased with the selective reduction of multiple gestations and with earlier MMC repair. After historically reducing multiple gestations in the same uterine horn to minimize growth restriction, we have since stopped this practice due to its association with fetal demise. As the placental structure for sheep is cotyledonary and therefore overlaps between multiple gestations in the same horn, reduction of a fetus may result in regression of the cotyledons in the same horn, negatively affecting the other gestation. The association of earlier MMC defect repair and fetal loss remains unclear, though this may be due to cumulative stress of fetal surgical intervention and membrane disruption.

A number of plausible risk factors for fetal loss are not captured in this study including fetal blood loss and type of treatment. We did not record fetal blood loss because the amount is minimal, saturating significantly less than a single $4 \times 4 \mathrm{~cm}$ gauze. Based on visual correlates, we estimate our fetal blood loss to be 1-2 mL per MMC defect creation and less than $1 \mathrm{~mL}$ per MMC repair [24]. The lamb fetoplacental blood volume at the time of defect creation is approximately $22 \mathrm{~mL}$ based on their average 0.18 $\mathrm{kg}$ weight, which corresponds to a 16- or 17-week human fetus [25]. Less than $10 \%$ total blood volume hemorrhage, which is caused in MMC defect repairs, should be tolerated well given that human fetuses replace half of any lost blood volume within $30 \mathrm{~min}$ [26].

We did not find any evidence of operator experience on fetal loss. Academic year, which best accounts for the learning curve of general surgery research fellows during surgeries, was not associated with fetal loss. Anecdotally, we have observed that new learners tend to increase the duration of each of the procedures; however, operative time was not associated with fetal loss.

Infectious causes of abortion in sheep include Campylobacter sp., Chlamydia sp., Toxoplasma sp., Listeria sp., Brucella sp., Salmonella sp., border disease virus, and Cache Valley virus [27]. While our practice is to send any fetuses with suspected pathology for testing, none of the aforementioned infectious agents have been documented. One fetal death occurred following a fungal infection (species not reported), which may have resulted from amniotic fluid contamination.

Chorioamniotic membrane separation is a known risk of fetal surgery in humans associated with premature rupture of membranes and early delivery [28-30]. Membrane separation in humans is more commonly seen when performing hysterotomy at an earlier gestation [28, 30]. In our ovine model, we try to minimize the separation; however, we do not have a documented spectrum of separation, and therefore did not account for its effects in this study.

\section{Conclusion}

The fetal ovine model of MMC is complicated by high rates of fetal loss, which can be minimized by not performing reductions, performing MMC defect repairs later in gestation, and performing Cesarean deliveries.

\section{Acknowledgements}

The authors thank Yifan Wei and Kurt Miura for their help collecting the data, William Ferrier, Amy Lesneski, and Linda Talken for their assistance in the perioperative care and management of our research animals, and Cook Biotech for their generous donation of the extracellular matrix material.

\section{Statement of Ethics}

The University of California Davis Institutional Animal Care and Use Committee (IACUC) approved all animal protocols, and all animal care was in compliance with the Guide for the Care and 
Use of Laboratory Animals. All facilities used during the study period were accredited by the Association for the Assessment and Accreditation of Laboratory Animal Care International.

\section{Disclosure Statement}

The authors have no conflicts of interest to declare.

\section{Funding Sources}

This work was partially supported by funding from the California Institute of Regenerative Medicine (grants \#PC1-08103, \#CLIN1-11404), Shriners Hospital for Children (grants \#85120NCA-16, 85108-NCA-19), the NIH (grants \#5R01NS100761-02, \#1R03HD091601-01) and March of Dimes Foundation (grant
\#5FY1682). L.A.G. was also supported by the National Center for Advancing Translational Sciences, National Institutes of Health, through grant number UL1TR001860. The content is solely the responsibility of the authors and does not necessarily represent the official views of the NIH.

\section{Author Contributions}

Study conception and design: Laura A. Galganski, Diana L. Farmer, Benjamin A. Keller, James C. Becker. Drafting of manuscript: Laura A. Galganski. Critical Revision of Manuscript: Kaeli J. Yamashiro, Christopher D. Pivetti, Payam Saadai, Aijun Wang, Diana L. Farmer. Analysis and interpretation of data: Laura A. Galganski, Kaeli J. Yamashiro. Acquisition of data: Laura A. Galganski, Christopher D. Pivetti, Benjamin A. Keller, James C. Becker, Erin G. Brown, Payam Saadai, Shinjiro Hirose.

\section{References}

1 Adzick NS. Fetal myelomeningocele: natural history, pathophysiology, and in-utero intervention. Semin Fetal Neonatal Med. 2010 Feb; 15(1):9-14

2 Heffez DS, Aryanpur J, Hutchins GM, Freeman JM. The paralysis associated with myelomeningocele: clinical and experimental data implicating a preventable spinal cord injury. Neurosurgery. 1990 Jun;26(6):987-92.

3 Heffez DS, Aryanpur J, Rotellini NA, Hutchins GM, Freeman JM. Intrauterine repair of experimental surgically created dysraphism. Neurosurgery. 1993 Jun;32(6):1005-10.

4 Meuli M, Meuli-Simmen C, Hutchins GM, Yingling CD, Hoffman KM, Harrison MR, et al. In utero surgery rescues neurological function at birth in sheep with spina bifida. Nat Med. 1995 Apr;1(4):342-7.

5 Meuli M, Meuli-Simmen C, Yingling CD, Hutchins GM, Timmel GB, Harrison MR, et al. In utero repair of experimental myelomeningocele saves neurological function at birth. J Pediatr Surg. 1996 Mar;31(3):397402.

6 Adzick NS, Thom EA, Spong CY, Brock JW 3rd, Burrows PK, Johnson MP, et al.; MOMS Investigators. A randomized trial of prenatal versus postnatal repair of myelomeningocele. N Engl J Med. 2011 Mar;364(11):993-1004.

7 Kabagambe S, Keller B, Becker J, Goodman L, Pivetti C, Lankford L, et al. Placental mesenchymal stromal cells seeded on clinical grade extracellular matrix improve ambulation in ovine myelomeningocele. J Pediatr Surg. 2017 Oct:53(1):178-82.

8 Vanover M, Pivetti C, Lankford L, Kumar P, Galganski L, Kabagambe S, et al. High density placental mesenchymal stromal cells provide neuronal preservation and improve motor function following in utero treatment of ovine myelomeningocele. J Pediatr Surg. 2019 Jan; 54(1):75-9.
9 Kabagambe SK, Lee CJ, Goodman LF, Chen YJ, Vanover MA, Farmer DL. Lessons from the Barn to the Operating Suite: A Comprehensive Review of Animal Models for Fetal Surgery. Annu Rev Anim Biosci. 2018 Feb; 6(1):99-119.

10 Meuli M, Meuli-Simmen C, Yingling CD, Hutchins GM, Hoffman KM, Harrison MR, et al. Creation of myelomeningocele in utero: a model of functional damage from spinal cord exposure in fetal sheep. J Pediatr Surg. 1995 Jul;30(7):1028-32.

11 Eggink AJ, Roelofs LA, Feitz WF, Wijnen RM, Lammens MM, Mullaart RA, et al. Delayed intrauterine repair of an experimental spina bifida with a collagen biomatrix. Pediatr Neurosurg. 2008;44(1):29-35.

12 Brown EG, Keller BA, Pivetti CD, Farmer DL Innate healing in the fetal sheep model of myelomeningocele: A standardized defect grading system. J Pediatr Surg. 2015 Jul;50(7): 1134-6.

13 Meuli-Simmen C, Meuli M, Hutchins GM, Harrison MR, Buncke HJ, Sullivan KM, et al. Fetal reconstructive surgery: experimental use of the latissimus dorsi flap to correct myelomeningocele in utero. Plast Reconstr Surg. 1995 Oct;96(5):1007-11.

14 Yoshizawa J, Sbragia L, Paek BW, Sydorak RM, Yamazaki Y, Harrison MR, et al. Fetal surgery for repair of myelomeningocele allows normal development of the rectum in sheep. Pediatr Surg Int. 2003 May;19(3):1626.

15 Saadai P, Nout YS, Encinas J, Wang A, Downing TL, Beattie MS, et al. Prenatal repair of myelomeningocele with aligned nanofibrous scaffolds-a pilot study in sheep. J Pediatr Surg. 2011 Dec;46(12):2279-83.
16 Saadai P, Wang A, Nout YS, Downing TL, Lofberg K, Beattie MS, et al. Human induced pluripotent stem cell-derived neural crest stem cells integrate into the injured spinal cord in the fetal lamb model of myelomeningocele. J Pediatr Surg. 2013 Jan;48(1): 158-63.

17 Wang A, Brown EG, Lankford L, Keller BA, Pivetti CD, Sitkin NA, et al. Placental mesenchymal stromal cells rescue ambulation in ovine myelomeningocele. Stem Cells Transl Med. 2015 Jun;4(6):659-69.

18 Brown EG, Saadai P, Pivetti CD, Beattie MS Bresnahan JC, Wang A, et al. In utero repair of myelomeningocele with autologous amniotic membrane in the fetal lamb model. J Pediatr Surg. 2014 Jan;49(1):133-7.

19 Brown EG, Keller BA, Lankford L, Pivetti CD, Hirose S, Farmer DL, et al. Age Does Matter: A Pilot Comparison of Placenta-Derived Stromal Cells for in utero Repair of Myelomeningocele Using a Lamb Model. Fetal Diagn Ther. 2016;39(3):179-85.

20 Brown EG, Keller BA, Pivetti CD, Sitkin NA, Wang A, Farmer DL, et al. Development of a locomotor rating scale for testing motor function in sheep. J Pediatr Surg. 2015 Apr;50(4): 617-21.

21 Burgos L, Encinas JL, García-Cabezas MA, Peiró JL, López-Santamaría M, Jaureguízar E. Bladder changes after several coverage modalities in the surgically induced model of myelomeningocele in lambs. Actas Urol Esp. 2014 Jan-Feb;38(1):55-61.

22 Encinas Hernández JL, Soto C, García-Cabezas MA, Pederiva F, Garriboli M, Rodríguez $\mathrm{R}$, et al. Brain malformations in the sheep model of myelomeningocele are similar to those found in human disease: preliminary report. Pediatr Surg Int. 2008 Dec;24(12): 1335-40. 
23 Eggink AJ, Roelofs LA, Feitz WF, Wijnen RM, Mullaart RA, Grotenhuis JA, et al. In utero repair of an experimental neural tube defect in a chronic sheep model using biomatrices. Fetal Diagn Ther. 2005 Sep-Oct;20(5):33540.

24 Ali Algadiem E, Aleisa AA, Alsubaie HI, Buhlaiqah NR, Algadeeb JB, Alsneini HA. Blood Loss Estimation Using Gauze Visual Analogue. Trauma Mon. 2016 May;21(2): e34131.

25 Morris JA, Hustead RF, Robinson RG, Haswell GL, Morgan CA, Gobuty A. Measurement of fetoplacental blood volume in the hu- man previable fetus. Am J Obstet Gynecol. 1974 Apr;118(7):927-34.

26 Brace RA. Fetal blood volume responses to acute fetal hemorrhage. Circ Res. 1983 Jun; 52(6):730-4.

27 Tibary A. Abortion in Sheep. Whitehouse Station: Merck; 2016 [updated 2016 Jul 11]. Available from: https://www.merckvetmanual.com/reproductive-system/abortion-inlarge-animals/abortion-in-sheep

28 Soni S, Moldenhauer JS, Spinner SS, Rendon N, Khalek N, Martinez-Poyer J, et al. Chorioamniotic membrane separation and preterm premature rupture of membranes complicat- ing in utero myelomeningocele repair. Am J Obstet Gynecol. 2016 May;214(5):647.e1-7.

29 Johnson MP, Bennett KA, Rand L, Burrows PK, Thom EA, Howell LJ, et al. The Management of Myelomeningocele Study: obstetrical outcomes and risk factors for obstetrical complications following prenatal surgery. Am J Obstet Gynecol. 2016;215(6):778.e1-.e9.

30 Wilson RD, Johnson MP, Crombleholme TM, Flake AW, Hedrick HL, King M, et al. Chorioamniotic membrane separation following open fetal surgery: pregnancy outcome. Fetal Diagn Ther. 2003 Sep-Oct;18(5): 314-20. 